\title{
Influence of type and orientation of thin-walled beams on the interaction effectiveness with sandwich panels
}

\author{
K. Ciesielczyk \& R. Studziński \\ Institute of Building Engineering, Poznan University of Technology, Poznań, Poland
}

\begin{abstract}
In the paper, the problem of the interaction between thin-walled beams with sandwich panels has been presented. The sandwich panels consist of steel external facings and the polyurethane foam core. The $\mathrm{Z}$ and $\mathrm{C}$ cross-section shapes and their various mutual orientations have been considered. The stabilization effect provided by the sandwich panels was investigated in a full-scale laboratory experiment and then compared with the numerical model. The full-scale test allowed for validation of the numerical model created in the Abaqus/CEA environment. The Newton-Raphson procedure with geometrical and material nonlinearity was implemented in order to perform the numerical computations.
\end{abstract}

\section{MOTIVATION}

In recent times, thin-walled beams are more and more frequently used as elements of a steel hall system (purlins, wall beams, construction of casings and eaves beams). The main advantage of designing structures with thin-walled elements is a favorable mass to bearing capacity ratio and mass to stiffness ratio. On the other hand, structures with thin-walled elements also have a negative effect due to the large slenderness of its walls - thin-walled cross sections are susceptible to the local loss of stability. Both local loss of stability (local buckling) as well as distortional buckling and global buckling (flexural, torsional, lateral-torsional and flexurallateral) are the most common forms of the thin-walled beams instabilities.

The interaction between structural elements is an important topic. In this case, structural elements which are understood as a roof or a wall sheathing are interacting with a steel supporting framework. Trapezoidal sheets and sandwich panels are commonly used as a roof or wall sheathing in steel structures. These types of sheathings are characterized by a high bending stiffness (plate behavior) and a high shear stiffness (diaphragm behavior). Therefore they can provide lateral and torsional buckling restraint of steel elements. Taking into account the mechanical interaction between a steel supporting framework and an external sheathing provide possibility for computing the construction as three-dimensional plate-diaphragm-rod load-bearing structures. For example Lucas et al. 1997a, b introduced simplified model and a full model which defines the interaction between thin walled beams and the sandwich panels. The procedure which is capable of determination the value of critical buckling moment of the thin-walled beam restrained by trapezoidal sheeting was proposed by Ye et al. 2002, Li $2004 \& \mathrm{Chu}$ et al. 2004. It is worth to mention that taking into the consideration the described influence may result in the global weight of a structure reduction and consequently, lowering the total cost.

The subject matter of steel elements interacting with trapezoidal sheets is widely discussed in the literature and has been reflected in EN 1993-1-3 code guidelines. In recent years, sandwich panels are more often used as elements of hall casing because of their good mechanical and thermal properties. The increasing popularity in using this type of sheathing has 
prompted researchers to also analyze the interaction of steel construction and sandwich panels, which recently were not used in common for the stiffening the structural elements. Over the last decade, there have been carried out some laboratory and numerical researches by Dürr 2008, Dürr \& Misiek 2011 which confirm that not only the trapezoidal sheets but also sandwich panels can provide the lateral restrain of the thin-walled elements. This topic was also discussed in research projects, which resulted in developing methods defining the interaction between sandwich panels and thin-walled beams. Furthermore, these methods have been also included in the European recommendations.

\section{PROBLEM FORMULATION}

The analysis was carried out on cold-formed sections which were made of $1.5 \mathrm{~mm}$ thick and $220 \mathrm{~mm}$ width sheet metal with the total length equal to $3300 \mathrm{~mm}$. Two shapes of crosssections were formed from steel sheets: " $Z$ " and " $C$ " with dimensions given in Figure 1.

So far, the analyses of the interaction between thin-walled beams and sandwich panels have been conducted for classical orientation of the thin-walled elements, see ZZ-1 and CC-1 models depicted in Figure 2. In this paper, authors had decided to analyze different orientations of thin-walled beams. The aim of this research was the analysis of the influence of thinwalled beams orientation stabilized by the sandwich panels on the thin-walled element buckling form. Nine different beam orientations have been analyzed: three of the Z-beams (Figure 2a), three of the C-beams (Figure 2b) and three with mixed composition of C- and Z- beams (Figure 2c).
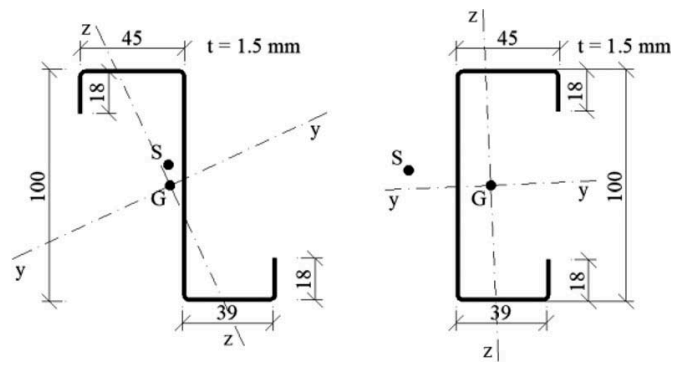

Figure 1. The dimensions of analyzed cross-sections, where $\mathrm{S}$ and $\mathrm{G}$ is location of the shear center and center of gravity, respectively.

a)

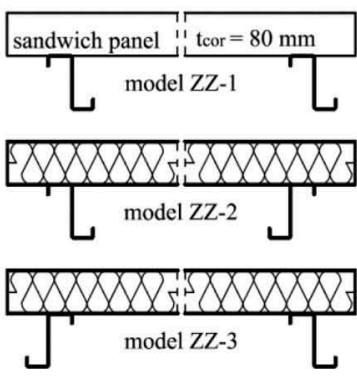

b)

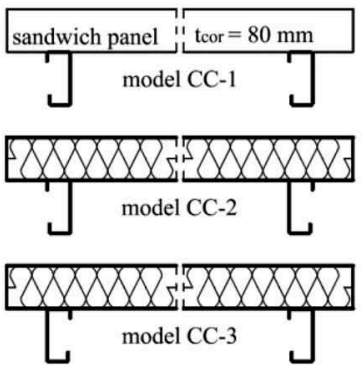

c)

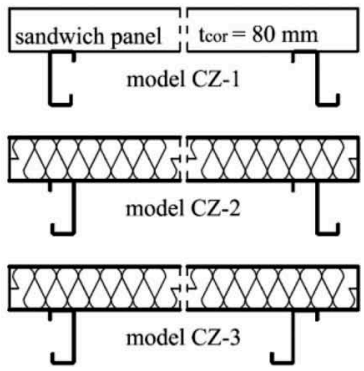

Figure 2. The relative orientation of the thin-walled elements - description in main text. 


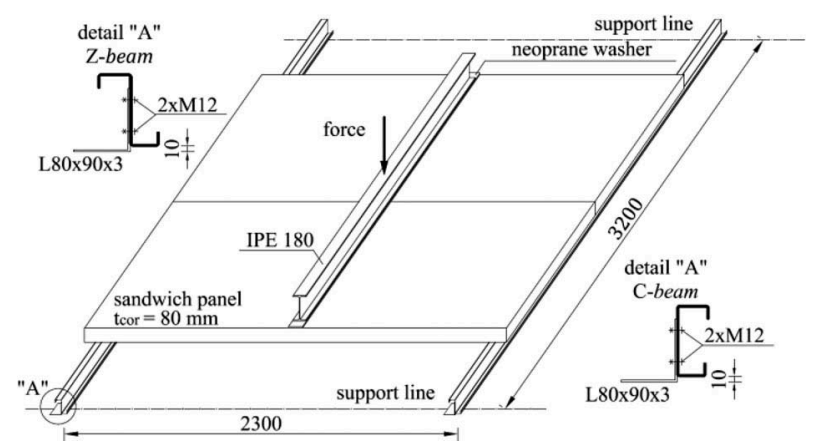

Figure 3. Scheme of the laboratory test-bed (Ciesielczyk \& Studziński, 2017).

\section{LABORATORY BACKGROUND}

Laboratory experiments cover full-scale experiments and material tests. Two thin-walled beams with the length equal to $3300 \mathrm{~mm}$ were stiffened by two sandwich panels with the width equal to $1100 \mathrm{~mm}$. The sandwich panel core of a thickness $100 \mathrm{~mm}$ was made of polyurethane foam. The scheme of the laboratory test-bed is presented in Figure 3. Two beam crosssections were taken under consideration: Z-beam and C-beam with dimensions given in Figure 1. Four angle cleats of a length $0.1 \mathrm{~m}$ were used in order to avoid the local compression of the thin-walled beam at the supports. During experimental tests two beam arrangements were investigated: ZZ-1 model (Ciesielczyk \& Studziński, 2017) and CC-1 model (Studziński \& Ciesielczyk, 2016). The sandwich panels which were used in the experiment consisted of two zinc-coated steel facings and thick and soft polyurethane core. The following geometrical dimensions of sandwich panel layers were measured: thickness of the core $d_{c}=80 \mathrm{~mm}$, thickness of the external $t_{F e}=0.594 \mathrm{~mm}$ and internal facings $t_{F i}=0.490 \mathrm{~mm}$. The aspect of the connection stiffness was considered in other paper (Studziński \& Ciesielczyk, 2019).

In order to determine the material properties, such as: Young's modulus, yield strength, ultimate tensile strength and stress-strain characteristic, the tensile tests have been carried out for the material samples of sandwich panel facings (12 samples) and thin-walled beams (6 samples). A tensile specimens had a shape of standardized cross-section sample and consisted of two shoulders and a gage between them. The dimensions of the prepared samples are presented in Figure 4a. Conducted tensile tests indicated that Young's modulus for the steel facing material and for the steel thin-walled beam material is equal to $190 \mathrm{GPa}$ and $198 \mathrm{GPa}$

a)

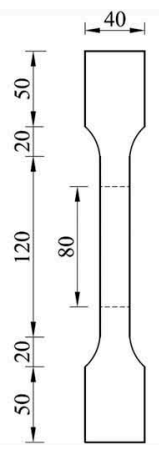

b)

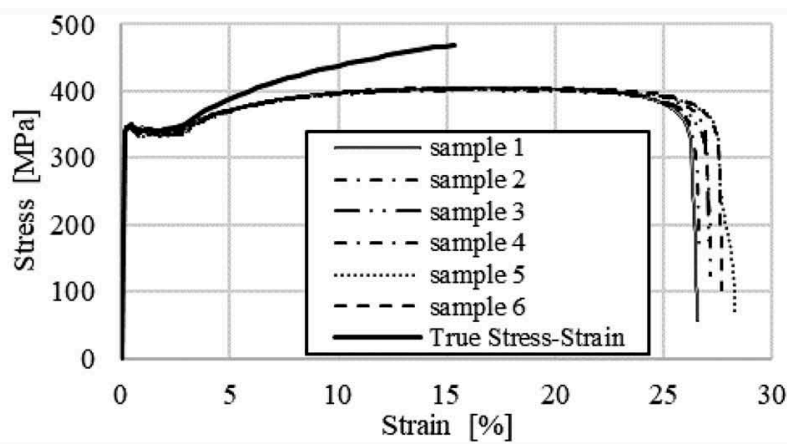

Figure 4. Tensile test: a) the steel sample dimensions, b) the stress-strain curve for steel from beam. 
respectively. The value of the Poisson's ratio for steel is equal to 0.3 . On the basis of the performed tests, the steel which was considered as element's materials was defined as mild steel with a plasticity effect (significant increase of strain without stress increase). The stress-strain curves obtained from the experiment for thin-walled beam steel ( 6 samples) are presented in Figure $4 \mathrm{~b}$. The average value of the upper yield strength determined by the experiment is equal to $348.87 \mathrm{MPa}$ while the value of ultimate tensile strength equals 402.72 MPa.

\section{LABORATORY BACKGROUND}

The numerical output model had been defined within the Abaqus/CEA environment (the model was also presented in Ciesielczyk \& Studziński, 2017). The numerical model had been verified and validated by the laboratory experiments described in the above subsection. The created numerical model reflected the laboratory experiment thus it consists of angle cleats, thin-walled beams with various shapes and orientations, sandwich panels, and an I-beam.

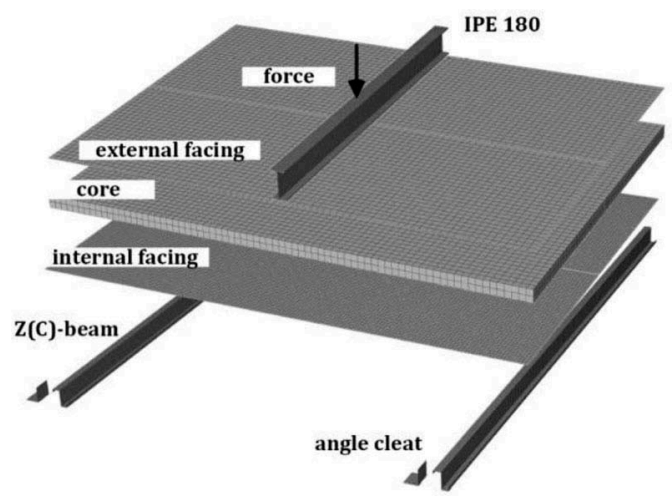

Figure 5. Scheme of the numerical model.

All steel properties used in the numerical model were determined by the laboratory experiments. The true stress-strain curve implemented into the numerical model has been presented in Figure $4 \mathrm{~b}$ by the continuous line. The true stress and strain were determined by the following formulas:

$$
\begin{gathered}
\sigma_{\text {true }}=\sigma_{\text {nom }}\left(1+\varepsilon_{\text {nom }}\right), \\
\varepsilon_{\text {true }}=\ln \left(1+\varepsilon_{\text {nom }}\right), \\
\varepsilon_{\text {true }}^{p l}=\left(\varepsilon_{\text {true }}-\sigma_{\text {true }}\right) / E,
\end{gathered}
$$

where: $\sigma_{\text {true }}$ represents true stress, $\sigma_{\text {nom }}$ represents nominal stress (engineering), $\varepsilon_{\text {nom }}$ represents nominal strain (engineering), $\varepsilon_{\text {true }}$ represents true strain, and $\varepsilon_{\text {true }}{ }^{p l}$ represents plastic true strain (required by Abaqus).

The properties of the sandwich panel core material such as: the shear modulus $\left(G_{C}=3.2\right.$ $\mathrm{MPa})$ and the Poisson ratio $\left(v_{C}=0.05\right)$ have been adopted from the previous work (Studziński, 2019). The non-linear stress-strain characteristic was used in the numerical model. The load in the numerical model consisted of: component's own weight and the concentrated force traversed into an uniformly distributed load by the I-beam. The boundary conditions have been applied to angle cleats in order to reflect the real connection with the support structure. Furthermore, in order to reduce the computation time the symmetry boundary conditions have been applied (the numerical model has been twice reduced). In order to obtain the nonlinear 
Table 1. Dimensions and type of the finite elements.

\begin{tabular}{llll}
\hline Model component & FE type & FE size in $[\mathrm{mm}]$ & number of FE \\
\hline IPE & C3D8R & $10 \times 10 \times 10$ & 5940 \\
External facing & S4R & $40 \times 40$ & 1998 \\
Core & C3D8R & $40 \times 40 \times 40$ & 4050 \\
Internal facing & S4R & $5 \times 5$ & 33110 \\
Thin-walled beam & S4R & $5 \times 5$ & 14190 \\
Angle cleat & S4R & $5 \times 5$ & 680 \\
\hline
\end{tabular}

static response, the Newton-Raphson procedure with Full Newton solution technique was adopted. All components of the model have been modeled by shell and solid finite elements. Their dimensions and types are presented in the Table 1, where according to the Abaqus documentation C3D8R is a 8-node linear brick finite element with reduced integration and hourglass control while S4R is a 4-node doubly curved thin or thick shell finite element with reduced integration, hourglass control, and finite membrane strains.

\section{DISCUSSION OF THE RESULTS}

From the assumed nine different beam orientations the following groups can be distinguished: the thin-walled beams with the upper flange directed in the same direction (ZZ-1, CC-1, CZ-2), the thin-walled beams with the upper flange directed "outside" (ZZ-2, CC-2, CZ-3), and the thin-walled beams with the upper flange directed "inside" (ZZ-3, CC-3, ZC1). The $C$ and $Z$ cross-sections have the same surface area and therefore the same self-weight per unit length, nevertheless the important differences between considered cross-sections refer to the geometrical characteristics influencing the size of the elastic critical bending moment, see Table 2.

According to data presented in Table 2, it can be noticed that the $\mathrm{Z}$ cross-section is characterized by higher warping properties than the $\mathrm{C}$ cross-section. The higher warping properties $\left(I_{t}, I_{z}, I_{\omega}\right)$, the higher magnitude of the elastic critical moment for lateral torsional buckling can be provided by the cross-section. Additionally, the position of the applied transverse load with regard to the shear center is significantly closer for $\mathrm{Z}$ than $\mathrm{C}$ cross-section. Therefore this parameter - which represent the point at the cross-section where the application of load does not cause its twisting - is favorable for $\mathrm{Z}$ cross-section. In other words, the torsional stresses, from the load of the same magnitude and way of application, are smaller for $Z$ than $C$ crosssection. On the other hand, principal central axes of both considered cross-sections do not coincide with the loading plane. This leads to biaxial bending nevertheless, in the case of $\mathrm{C}$ cross-section, the inclination angle of the principal central axes (from the loading plane) is 20 times smaller compared with $\mathrm{Z}$ cross-section. It means that the biaxial bending moment decomposition produces a larger bending moment against the weaker axis in the case of $\mathrm{Z}$ cross-section than in the case of $\mathrm{C}$ cross-section.

Table 2. Selected geometrical characteristic.

\begin{tabular}{lllll}
\hline No. & Geometrical characteristic & Z-section & C-section & Difference \\
\hline 1. & $I_{t}$ - torsion constant & $0.02 \mathrm{~cm}^{4}$ & $0.02 \mathrm{~cm}^{4}$ & $0.0 \%$ \\
2. & $I_{z}$ - second moment of area about the weak axis & $14.89 \mathrm{~cm}^{4}$ & $8.61 \mathrm{~cm}^{4}$ & $42.2 \%$ \\
3. & $I_{\omega}$ - warping constant & $259.00 \mathrm{~cm}^{6}$ & $209.00 \mathrm{~cm}^{6}$ & $19.3 \%$ \\
4. & $\alpha_{0}$ - inclination angle of the principal axes & $24.90^{\circ}$ & $2.50^{\circ}$ & $90.0 \%$ \\
5. & $y_{s}$ - distance of the shear center from the web & $2.41 \mathrm{~mm}$ & $-21.39 \mathrm{~mm}$ & $987.6 \%$ \\
\hline
\end{tabular}




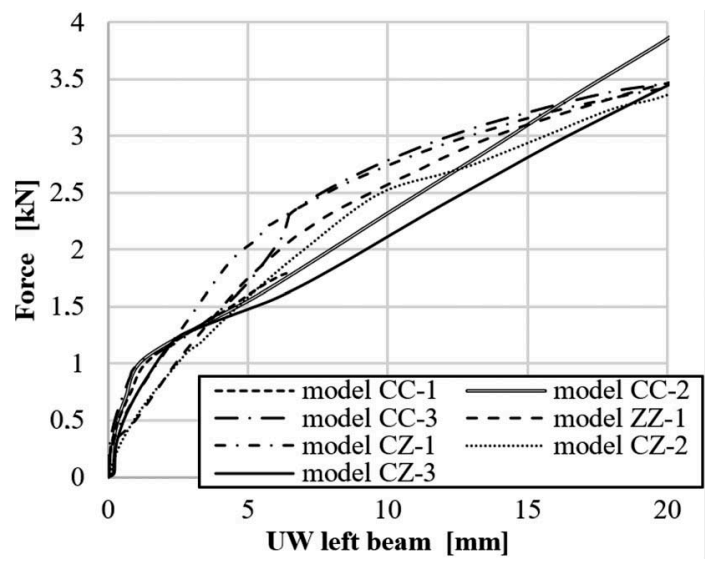

Figure 6. Load-displacement paths of the middle point of a bottom flange of the thin-walled beam.

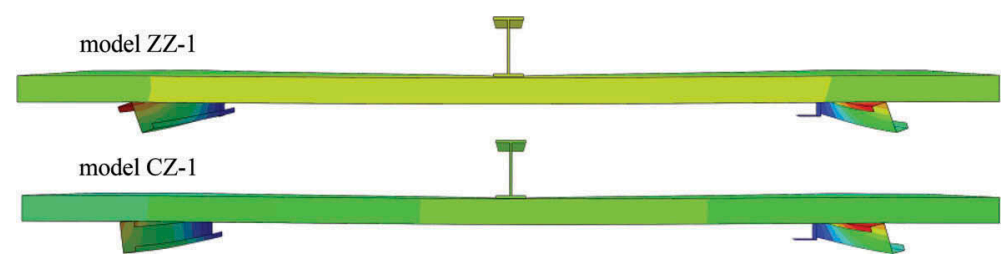

Figure 7. Maps of displacements for selected models - the cross section in the middle of the sandwich panel.

The resultant load-displacement paths of the middle point of the bottom flange of the left thin-walled beams is presented in Figure 6. The results of the ZZ-2 and ZZ-3 are not included due to the lack of convergence of the nonlinear FEA analysis. The deformation maps of three selected models are presented in Figure 7.

\section{CONCLUSIONS}

The following conclusion can be formulated. Firstly it was observed that the $\mathrm{Z}$ cross-sections are sensitive to the biaxial bending while the $\mathrm{C}$ cross-sections to twisting which leads to an initial greater stiffness of the system with C-beams than in the case of the system with Z-beams. This is due to:

- the initial in-plane bending of the C-beams because of small inclination angle of the principal axes with respect to the load plane, and

- the initial biaxial bending of the Z-beams because of large inclination angle of the principal axes with respect to the load plane.

Secondly the further increase of the loading (above "initial" i.e. in our cases above $1 \mathrm{kN}$ ) leads to:

- significant stiffness reduction of C-beams due to twisting (large distance between loading plane and the shear center), and

- gradual decrease of flexural stiffness of Z-beams (small distance between loading plane and the shear center). 


\section{ACKNOWLEDGEMENT}

This work was supported by the by Poznan University of Technology Grant no. 0412/SBAD/ 0046 .

\section{REFERENCES}

Lucas, R.M., Al-Bermani, F.G.A. \& Kitipornchai, S. 1997. Modeling of cold-formed purlins - sheeting systems - Part 1. Full model. Thin-Walled Structures, 27(3), pp. 223-243.

Lucas, R.M., Al-Bermani, F.G.A. \& Kitipornchai, S. 1997. Modeling of cold-formed purlins - sheeting systems - Part 2. Simplified model. Thin-Walled Structures, 27(4), pp. 263-286.

Ye, Z.M., Kettle, R., Li, L.Y. \& Schafer, B. 2002. Buckling behaviour of cold-formed zet-purlins partially restrained by steel sheeting. Thin-walled Structures, 40, pp. 853-864.

Li, L.Y. 2014. Lateral-torsional buckling of cold-formed zet purlins partial laterally restrained by metal sheeting. Thin-Walled Structures, 42, 7, pp. 995-1011.

Chu, X.T., Kettle, R. \& Li, L.Y. 2001. Lateral-torsional buckling analysis of partial laterally restrained thin-walled channel sections beams. Jour. of Constr. Steel Research, 60, 8, pp. 1159-1175.

EN 1993-1: Design of Steel Structures. Part 1-3: General rules - Supplementary rules for cold-formed members and sheeting, Brussels, 2001.

Dürr, M. 2008. Die Stabilisierung biegedrillknickgefährdeter Träger durch Sandwichelemente und Trapezbleche, $\mathrm{PhD}$ dissertation, Karlsruhe.

Dürr, M., Misiek, T. \& Saal H. 2011. The torsional resistant of sandwich panels to resist the lateral torsional buckling, Steel Construction, 4, pp. 251-258.

European Recommendations on the Stabilization of Steel Structures by Sandwich Panels, International Council for Research and Innovation in Building and Construction, 2013.

Ciesielczyk, K. \& Studziński, R. 2017. Experimental and numerical investigation of stabilization of thin-walled Z-beams by sandwich panels, Jour. of Constr. Steel Research, 133, pp. 77-83.

Studziński, R. \& Ciesielczyk, K. 2016. Experimental investigation of the stabilization of the C-section purlins by sandwich panels, Recent Progress in Steel and Composite Structures: Proceedings of the XIII International Conference on Metal Structures, pp. 101-106.

Studziński, R. \& Ciesielczyk, K. 2019. Connection stiffness between thin-walled beam and sandwich panel. Journal of Sandwich Structures \& Materials vol. 21, Issue 6, pp. 2042-2056.

Getting Started with Abaqus: Keyword Edition, 6.14, access online 2020.11.15 http://130.149.89.49:2080/ v6.14/books/gsk/default.htm

Studziński, R. 2019. Optimal design of sandwich panels with hybrid core, Journal of Sandwich Structures \& Materials, vol. 21, Issue 7, pp. 2181-2193. 